\title{
Comparative genotypic and pathogenic examination of Campylobacter concisus isolates from diarrheic and non-diarrheic humans
}

\author{
Lisa D Kalischuk, G Douglas Inglis
}

\begin{abstract}
Background: Campylobacter concisus is an emerging enteric pathogen, yet it is commonly isolated from feces and the oral cavities of healthy individuals. This genetically complex species is comprised of several distinct genomospecies which may vary in pathogenic potential.

Results: We compared pathogenic and genotypic properties of $C$. concisus fecal isolates from diarrheic and healthy humans residing in the same geographic region. Analysis of amplified fragment length polymorphism (AFLP) profiles delineated two main clusters. Isolates assigned to AFLP cluster 1 belonged to genomospecies A (based on genomospecies-specific differences in the $23 S$ rRNA gene) and were predominantly isolated from healthy individuals. This cluster also contained a reference oral strain. Isolates assigned to this cluster induced greater expression of epithelial IL-8 mRNA and more frequently contained genes coding for the zonnula occludins toxin and the S-layer RTX. Furthermore, isolates from healthy individuals induced greater apoptotic DNA fragmentation and increased metabolic activity than those from diarrheic individuals, and isolates assigned to genomospecies A (of which the majority were from healthy individuals) exhibited higher haemolytic activity compared to genomospecies B isolates. In contrast, AFLP cluster 2 was predominated by isolates belonging to genomospecies B and those from diarrheic individuals. Isolates from this cluster displayed greater mean epithelial invasion and translocation than cluster 1 isolates.

Conclusion: Two main genetically distinct clusters (i.e., genomospecies) were identified among C. concisus fecal isolates from healthy and diarrheic individuals. Strains within these clusters differed with respect to clinical presentation and pathogenic properties, supporting the hypothesis that pathogenic potential varies between genomospecies. ALFP cluster 2 isolates were predominantly from diarrheic patients, and exhibited higher levels of epithelial invasion and translocation, consistent with known roles for these factors in diarrhoeal disease. Conversely, isolates from healthy humans and AFLP cluster 1 or genomospecies A (which were predominantly isolated from healthy humans) exhibited increased haemolytic ability, apoptotic DNA fragmentation, IL-8 induction, and/or carriage of toxin genes. Given that this cluster contains an oral reference strain, it is possible that some of the AFLP cluster 1 isolates are periodontal pathogens and may cause disease, albeit via a different mechanism than those from AFLP cluster 2.
\end{abstract}

\section{Background}

Campylobacter species are one of the most common causes of human enteritis in North America (Centers for Disease Control and Prevention, U.S. Department of Agriculture, and Food and Drug Administration Collaborating Sites Foodborne Disease Active Survey

\footnotetext{
* Correspondence: Douglas.Inglis@agr.gc.ca

Agriculture and Agri-Food Canada, 5403-1 $1^{\text {st }}$ Avenue South, Lethbridge, AB T1J 4B1, Canada
}

Network [FoodNet]; Public Health Agency of Canada website, http://dsol-smed.phac-aspc.gc.ca/dsol-smed/ ndis/diseases/camp_e.html). While Campylobacter jejuni and Campylobacter coli are the most commonly isolated species, studies have also implicated 'cryptic' species within the genus, such as Campylobacter concisus, as causal agents of acute enteritis [1-4]. Compared to C. jejuni, C. concisus is fastidious to isolate as it is often sensitive to selective antimicrobial agents

\section{Biomed Central}


commonly-used in conventional isolation media, and generally requires a hydrogen-enriched atmosphere and a prolonged incubation period for growth [5]. As such, it is rarely cultured by standard isolation methods employed by many diagnostic facilities. Although knowledge of its clinical importance is limited, C. concisus has been cited as an emerging human pathogen [5,6].

Campylobacter concisus was originally isolated from periodontal lesions [7]. However, its pathogenic role in oral cavity infections remains uncertain, since it can also be isolated from healthy gingiva [8]. Additionally, $C$. concisus has been isolated from the feces of diarrheic patients [1-4], often in the absence of known pathogens. However, the bacterium is also frequently isolated from feces of asymptomatic patients, which has lead to the conclusion that it may be part of the normal intestinal microbiota $[9,10]$. Some evidence indicates that C. concisus may be an opportunistic pathogen. For example, Engberg et al. [9] observed that C. concisus was predominantly isolated from pediatric, elderly, and immunocompromised patients, in contrast to $C$. jejuni and $C$. coli which are typically isolated from diarrheic patients of all ages. Consequently because of its association with diarrheic, healthy, and immunocompromised patients, the specific role of $C$. concisus as a primary intestinal pathogen has yet to be firmly established.

Campylobacter concisus is a heterogeneous species complex comprised of several phenotypically indistinguishable but genetically distinct taxa ("genomospecies"). Numerous methods can be used to genetically separate the genomospecies, including PCR analysis of the 23S rRNA gene [11] and cluster analysis of amplified fragment length polymorphism (AFLP) or random amplified polymorphic DNA (RAPD) profiles [1,2]. Based on these typing methods, at least two main $C$. concisus genomospecies have been identified $[1,2,4,11]$.

Differences in pathogenicity amongst distinct genomospecies of some bacterial taxa $[12,13]$ support the notion that certain $C$. concisus genomospecies may be more likely than others to cause intestinal disease. While an early study by Van Etterijck et al. [10] concluded that $C$. concisus was not pathogenic given similar isolation rates from diarrheic and healthy children, genetic diversity of the isolates with respect to clinical presentation was not considered. A more recent study showed that isolates from healthy individuals were genetically distinct from those of diarrheal origin; however, differences in epithelial cytotoxicity between the two groups were not evident [2]. Additionally, cluster analysis of diarrheic isolate AFLP profiles delineated two main C. concisus genomospecies (designated genomospecies 1 and 2), which where characterized by type strains of oral and diarrheal origin, respectively [1]. Genomospecies 2 isolates were more frequently isolated from the stool of patients presenting with diarrhea in which no other pathogens were found, and bloody diarrhea was associated only with genomospecies 2 isolates. While these studies suggest that distinct $C$. concisus genomospecies may vary in their pathogenic ability, this has yet to be empirically examined.

Our understanding of Campylobacter pathogenesis is based primarily on $C$. jejuni. Its small, spiral shape coupled with flagella-mediated motility, allow $C$. jejuni to penetrate intestinal mucus [14] where it can then adhere to and invade intestinal epithelial cells. This bacterium can also translocate across the intestinal epithelium via a paracellular mechanism involving disruption of epithelial tight junctions $[15,16]$ or via a lipid raft-mediated transcellular mechanism [17]. C. jejuni also causes cellular cytotoxicity through the production of various toxins; cytolethal distending toxin (CDT) is a well-characterized toxin produced by most strains. The cytolethal distending toxin blocks cell proliferation in the G2/M phase resulting in cellular distension leading to the induction of apoptotic cell dealth [18]. This bacterium also induces intestinal epithelial secretion of interleukin-8 (IL-8), a pro-inflammatory chemoattractant that recruits neutrophils to the site of infection [19]. Cytolethal distending toxin-like activity has been reported for a majority of clinical C. concisus isolates [2], however the role that this toxin plays in pathogenesis is unknown. A membranebound haemolytic phospholipase is also produced by most clinical C. concisus isolates [20]. In addition, C. concisus genes coding for zonnula occludins toxin (zot) and a surface-layer protein belonging to the RTX (repeats in the structural toxins) family (S-layer $R T X$ ) have been recently identified [21]. Zonnula occludins toxin was first recognized as a toxin of Vibrio cholera, and disrupts the integrity of the intestinal epithelial barrier by targeting tight junctions [22]. S-layer RTX is a pore-forming toxin that is also found in Campylobacter rectus [23], and toxins within this family are recognized as important virulence factors [24].

The present study examines the hypothesis that the two main C. concisus genomospecies exhibit differences in pathogenicity. To address this hypothesis, we compared genotypic and pathogenic properties of C. concisus fecal isolates from diarrheic and asymptomatic ("healthy") humans. Specifically, genotypes of isolates were compared by AFLP analysis and a genomospeciesspecific $23 \mathrm{~S}$ rRNA gene PCR assay. Numerous pathogenic properties were also assessed including: (i) intestinal epithelial adherence, invasion, and translocation; (ii) ability to disrupt epithelial permeability, cause apoptotic DNA fragmentation, affect metabolic activity, and induce IL-8; hemolytic and cytotoxic activities; and (iii) carriage of toxin genes encoding CDT, ZOT, and Slayer RTX proteins. 


\section{Results}

\section{Genotypes}

Sequence analysis to confirm the identities of the clinical isolates indicated $>99 \% 16 \mathrm{~S}$ rRNA gene sequence similarity (near full-length) between the type strain C. concisus LMG7788 and all of the clinical isolates (GenBank accession numbers are listed in Table 1). Based on the genomospecies-specific PCR assay of the 23S rRNA gene [11], six and 12 of the 22 clinical C. concisus isolates were assigned to genomospecies A and B, respectively (Table 1). Three isolates generated PCR products for both genomospecies $A$ and $B$ primer sets (designated "A/B"), and one isolate did not amplify with either primer set (designated "X"). The type strain, LMG7788, was assigned to genomospecies A, consistent with previous observations [2]. Campylobacter concisus-specific PCR of the cpn60 gene was strongly positive for 21 isolates including the type strain and weakly positive for two isolates. Weak PCR products were likely due to mismatching of the PCR primers with their target gene (due to DNA sequence divergence), resulting in inefficient PCR amplification.
AFLP analysis indicated considerable genetic variability existed among the C. concisus isolates (Figure 1). Reproducibility between duplicate independent analyses of each isolate was $93.1 \pm 3.6 \%$ (mean \pm SD; Additional file 1). The isolates clustered into two phylotypes distinguished from each other at the 34\% similarity level. All isolates assigned to AFLP cluster 1 belonged to genomospecies A and included the type strain plus five isolates that were obtained from healthy $(\mathrm{n}=4)$ and diarrheic $(n=1)$ humans. Of the seventeen isolates assigned to AFLP cluster 2, 94\% (16/17) were isolated from diarrheic stools, and $71 \%$ belonged to genomospecies $B(n=12)$ while $17 \%$ belonged to genomospecies A/B $(n=3), 6 \%$ belonged to genomospecies A $(n=1)$, and one isolate was unassigned.

\section{Adherence, invasion, and translocation}

All C. concisus isolates exhibited comparable epithelial adherence to that of $C$. jejuni 81-176 (Table 2). The mean adherence of isolates belonging to genomospecies $\mathrm{A}$ did not differ from that of isolates belonging to genomospecies $\mathrm{B}\left(6.00 \pm 0.08 \log _{10} \mathrm{CFU} / \mathrm{ml}, \mathrm{n}=6\right.$ versus $6.28 \pm 0.20 \log _{10}$ $\mathrm{CFU} / \mathrm{ml}, \mathrm{n}=5$, respectively; $P=0.20)$. Similarly, mean

Table 1 Campylobacter concisus isolates

\begin{tabular}{|c|c|c|c|c|}
\hline Isolate & Source & Genomospecies $^{\mathrm{a}}$ & $\mathrm{cpn} 60^{\mathrm{b}}$ & GenBank ${ }^{c}$ Accession \# \\
\hline CHRB6 & Feces, diarrheic human & $B$ & + & HM_536958.0 \\
\hline CHRB39 & Feces, diarrheic human & $A / B$ & + & $\mathrm{n} / \mathrm{a}$ \\
\hline CHRB318 & Feces, diarrheic human & B & + & HM_536953.0 \\
\hline CHRB563 & Feces, diarrheic human & $A / B$ & + & HM_536957.0 \\
\hline CHRB1462 & Feces, diarrheic human & B & + & HM_536942.0 \\
\hline CHRB1569 & Feces, diarrheic human & B & + & HM_536943.0 \\
\hline CHRB1609 & Feces, diarrheic human & A & + & HM_536944.0 \\
\hline CHRB1656 & Feces, diarrheic human & B & + & HM_536945.0 \\
\hline CHRB1794 & Feces, diarrheic human & $A / B$ & + & HM_536946.0 \\
\hline CHRB2004 & Feces, healthy human & A & + & HM_536947.0 \\
\hline CHRB2011 & Feces, healthy human & A & + & HM_536948.0 \\
\hline CHRB2050 & Feces, diarrheic human & A & + & HM_536949.0 \\
\hline CHRB2167 & Feces, diarrheic human & B & + & $\mathrm{n} / \mathrm{a}$ \\
\hline CHRB2370 & Feces, diarrheic human & B & + & HM_536950.0 \\
\hline CHRB2691 & Feces, diarrheic human & B & + & HM_536951.0 \\
\hline CHRB2880 & Feces, diarrheic human & B & + & n/a \\
\hline CHRB3152 & Feces, diarrheic human & B & W & HM_536952.0 \\
\hline CHRB3235 & Feces, healthy human & $x$ & W & HM_536954.0 \\
\hline CHRB3287 & Feces, healthy human & A & + & HM_536955.0 \\
\hline CHRB3290 & Feces, healthy human & A & + & HM_536956.0 \\
\hline CHRB3559 & Feces, diarrheic human & B & + & $\mathrm{n} / \mathrm{a}$ \\
\hline CHRB3612 & Feces, diarrheic human & B & + & $\mathrm{n} / \mathrm{a}$ \\
\hline LMG7788 & Type strain, gingival sulcus & A & + & DQ_174166.1 \\
\hline
\end{tabular}

${ }^{a}$ Genomospecies determined using PCR assay for C. concisus $23 \mathrm{~S}$ rRNA gene. A/B indicates amplification with primer sets for both genomotype A and B. $\times$ indicates lack of PCR amplification with either primer set.

${ }^{b_{+}}$indicates PCR amplification of cpn60 gene; $w$ indicates weak PCR amplification.

${ }^{\mathrm{c}}$ Near full-length $16 \mathrm{~S}$ rRNA gene sequence. 


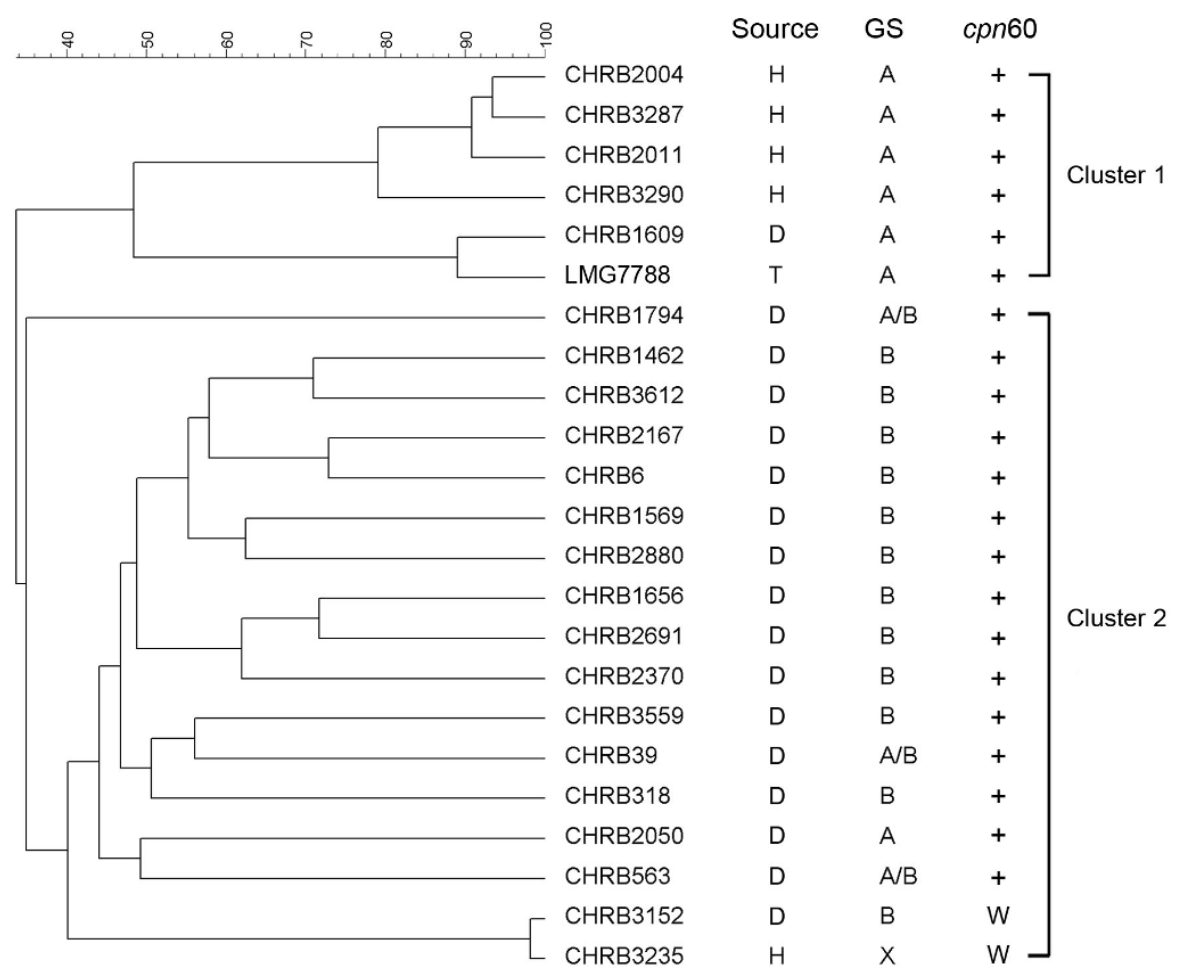

Figure 1 Dendrogram of AFLP profiles derived using the unweighted-pair group average linkage of Pearson-product-moment correlation coefficients from 22 Campylobacter concisus fecal isolates (designated CHRB) and the type strain (LMG7788). The bar indicates percentage similarity. LMG, Culture Collection of the Laboratorium voor Microbiologie, Gent, Belgium. H, healthy humans. D, diarrheic humans. T, type strain. GS, genomospecies as determined by PCR assay of the $23 \mathrm{~S}$ rRNA gene (2). A, genomospecies A. B, genomospecies B. A/B, indicates positive PCR for both genomospecies A and B. X, indicates negative PCR for both genomospecies A and B. cpn, C. concisus-specific cpn60 PCR. +, positive PCR. W, weak positive PCR. -, negative PCR.

adherence did not differ between isolates from diarrheic individuals and isolates from healthy volunteers $(6.25 \pm$ $0.11 \log _{10} \mathrm{CFU} / \mathrm{ml}, \mathrm{n}=9$ versus $6.08 \pm 0.14 \log _{10} \mathrm{CFU} / \mathrm{ml}$, $\mathrm{n}=5$, respectively; $P=0.35$ ), nor was it different for isolates assigned to AFLP cluster 1 versus cluster $2(5.00 \pm$ $0.09 \log _{10} \mathrm{CFU} / \mathrm{ml}, \mathrm{n}=5$ versus $6.30 \pm 0.11 \log _{10} \mathrm{CFU} / \mathrm{ml}$, $\mathrm{n}=9$, respectively; $P=0.09$ ).

Epithelial invasion for seven C. concisus isolates was equivalent to that of $C$. jejuni 81-176, including one of five isolates from AFLP cluster 1 and six of nine isolates for AFLP cluster 2 (Table 2). Isolates from AFLP cluster 2 were more invasive than cluster 1 isolates $(5.02 \pm 0.16$ $\log _{10} \mathrm{CFU} / \mathrm{ml}$ versus $4.27 \pm 0.30 \log _{10} \mathrm{CFU} / \mathrm{ml}$, respectively; $P=0.03)$. Mean invasion did not differ between isolates from diarrheic and healthy humans $(4.88 \pm 0.15$ $\log _{10} \mathrm{CFU} / \mathrm{ml}$ versus $4.52 \pm 0.41 \log _{10} \mathrm{CFU} / \mathrm{ml}$, respecively; $P=0.33$ ) or isolates belonging to genomospecies $\mathrm{A}$ and $\mathrm{B}\left(4.34 \pm 0.25 \log _{10} \mathrm{CFU} / \mathrm{ml}\right.$ versus $5.06 \pm 0.24$ $\log _{10} \mathrm{CFU} / \mathrm{ml}$, respectively; $\left.P=0.07\right)$. Adherence and invasion were positively correlated $\left(R^{2}=0.71 ; P<0.001\right)$.

Epithelial translocation was not different for any of the C. concisus isolates relative to C. jejuni 81-176 (Table 2). The mean translocation of $C$. concisus genomospecies B isolates was greater than isolates belonging to genomospecies A $\left(4.46 \pm 0.20 \log _{10} \mathrm{CFU} / \mathrm{ml}\right.$ versus $3.99 \pm 0.09$ $\log _{10} \mathrm{CFU} / \mathrm{ml}$, respectively; $\left.P=0.048\right)$, and isolates assigned to AFLP cluster 2 relative to cluster 1 ( $4.58 \pm$ $0.16 \log _{10} \mathrm{CFU} / \mathrm{ml}$ versus $3.99 \pm 0.11 \log _{10} \mathrm{CFU} / \mathrm{ml}$, respectively; $P=0.03$ ). Mean translocation between isolates from diarrheic and healthy humans did not differ $\left(4.48 \pm 0.15 \log _{10} \mathrm{CFU} / \mathrm{ml}\right.$ versus $4.17 \pm 0.25 \log _{10}$ $\mathrm{CFU} / \mathrm{ml}$, respecively; $P=0.26$ ). Translocation and invasion were weakly correlated $\left(R^{2}=0.27 ; P=0.059\right)$. There were no differences in the initial or final TER between Campylobacter-treated monolayers and the sterile broth control, and the final TER of all monolayers remained greater than $1000 \Omega \times \mathrm{cm}^{2}$ (Additional file 2) indicating that translocation occurred across an intact epithelial barrier. Also, FITC-dextran permeability did not differ for monolayers treated with $C$. concisus relative to the sterile broth control (Additional file 2).

\section{Hemolysis, DNA fragmentation, cytotoxicity, and metabolic activity}

All Campylobacter isolates exhibited hemolytic activity as defined by the percent lysis of sheep red blood cells 
Table 2 Intestinal epithelial adherence, invasion, and translocation of Campylobacter concisus isolates ${ }^{a}$

\begin{tabular}{ccccc}
\hline Isolate & $\begin{array}{c}\text { AFLP } \\
\text { cluster }\end{array}$ & $\begin{array}{c}\text { Adherence } \\
\left(\mathbf{l o g}_{10}\right. \\
\text { CFU/ml) }\end{array}$ & $\begin{array}{c}\text { Invasion } \\
\text { (log } 10 \\
\text { CFU/ml) }\end{array}$ & $\begin{array}{c}\text { Translocation } \\
\text { (log } 10 \\
\text { CFU/ml) }\end{array}$ \\
\hline CHRB2004 & 1 & $6.12 \pm 0.30^{\mathrm{b}}$ & $4.50 \pm 0.19$ & $4.31 \pm 0.65^{\mathrm{b}}$ \\
CHRB3287 & 1 & $6.03 \pm 0.28^{\mathrm{b}}$ & $4.72 \pm 0.11^{\mathrm{b}}$ & $3.74 \pm 0.18^{\mathrm{b}}$ \\
CHRB2011 & 1 & $6.11 \pm 0.21^{\mathrm{b}}$ & $4.62 \pm 0.18$ & $3.87 \pm 0.31^{\mathrm{b}}$ \\
CHRB3290 & 1 & $5.63 \pm 0.31^{\mathrm{b}}$ & $3.09 \pm 0.10$ & $3.84 \pm 0.22^{\mathrm{b}}$ \\
CHRB1609 & 1 & $6.06 \pm 0.06^{\mathrm{b}}$ & $4.44 \pm 0.12$ & $4.19 \pm 0.40^{\mathrm{b}}$ \\
& & & & \\
CHRB1794 & 2 & $6.30 \pm 0.26^{\mathrm{b}}$ & $4.53 \pm 0.13$ & $5.07 \pm 0.82^{\mathrm{b}}$ \\
CHRB6 & 2 & $6.03 \pm 0.03^{\mathrm{b}}$ & $5.06 \pm 0.22^{\mathrm{b}}$ & $4.38 \pm 0.96^{\mathrm{b}}$ \\
CHRB1569 & 2 & $5.82 \pm 0.14^{\mathrm{b}}$ & $4.60 \pm 0.23$ & $3.71 \pm 0.16^{\mathrm{b}}$ \\
CHRB2691 & 2 & $6.13 \pm 0.24^{\mathrm{b}}$ & $4.55 \pm 0.21$ & $4.86 \pm 0.63^{\mathrm{b}}$ \\
CHRB2370 & 2 & $6.43 \pm 0.20^{\mathrm{b}}$ & $5.25 \pm 0.13^{\mathrm{b}}$ & $4.74 \pm 0.45^{\mathrm{b}}$ \\
CHRB2050 & 2 & $6.06 \pm 0.06^{\mathrm{b}}$ & $4.64 \pm 0.11^{\mathrm{b}}$ & $3.97 \pm 0.44^{\mathrm{b}}$ \\
CHRB563 & 2 & $6.48 \pm 0.39^{\mathrm{b}}$ & $5.01 \pm 0.18^{\mathrm{b}}$ & $4.77 \pm 0.45^{\mathrm{b}}$ \\
CHRB3152 & 2 & $6.97 \pm 0.03^{\mathrm{b}}$ & $5.86 \pm 0.34^{\mathrm{b}}$ & $4.64 \pm 0.54^{\mathrm{b}}$ \\
CHRB3235 & 2 & $6.48 \pm 0.26^{\mathrm{b}}$ & $5.65 \pm 0.40^{\mathrm{b}}$ & $5.07 \pm 0.28^{\mathrm{b}}$ \\
& & & & \\
LMG7788 & 1 & $5.16 \pm 0.29^{\mathrm{b}}$ & $3.26 \pm 0.19$ & $4.00 \pm 0.31^{\mathrm{b}}$ \\
C. jejuni 81- & - & $6.26 \pm 0.34$ & $5.70 \pm 0.12$ & $5.41 \pm 0.49$ \\
176 & & & & \\
\hline
\end{tabular}

${ }^{\mathrm{a}}$ Data are means \pm SEM, $\mathrm{n}=3$.

${ }^{\mathrm{b}}$ Not significantly different from $C$. jejuni 81-176 $(P>0.05)$.

compared to the positive control $(=100 \%$; Table 3$)$. Mean hemolysis for genomospecies A isolates was greater than for isolates belonging to genomospecies $\mathrm{B}$ $(64.0 \pm 4.9 \%$ and $45.2 \pm 5.1 \%$, respectively; $P=0.027)$. Mean hemolysis did not differ between isolates from healthy and diarrheic individuals $(55.9 \pm 8.2 \%$ versus $52.0 \pm 5.2 \%$, respectively; $P=0.68$ ), nor between isolates assigned to AFLP clusters 1 and $2(63.9 \pm 6.0 \%$ versus $47.5 \pm 5.0 \%$, respectively; $P=0.06$ ). There was an inverse correlation between hemolysis and invasion $\left(\mathrm{R}^{2}\right.$ $=0.74 ; P<0.0001)$ and between hemolysis and adherence $\left(R^{2}=0.43 ; P<0.011\right)$. None of the $C$. concisus isolates caused significant epithelial cytotoxicity, whereas Campylobacter jejuni 81-176 and $\mathrm{H}_{2} \mathrm{O}_{2}$ induced cytotoxicity in agreement with previous observations [25] (Table 3).

Epithelial DNA fragmentation was significantly induced by all five C. concisus isolates from healthy individuals, $44.4 \%$ of the isolates from diarrheic humans (i.e., four of nine isolates), C. concisus LMG7788, C. jejuni 81-176, and the apoptosis-inducing agent, camptothecin (Table 3). Greater mean DNA fragmentation was observed for isolates from healthy volunteers compared to diarrheic individuals $\left(1.78 \pm 0.05 \mathrm{~A}_{370} \mathrm{~nm}\right.$ versus $1.48 \pm 0.08 \mathrm{~A}_{370} \mathrm{~nm}$, respectively; $\left.P=0.021\right)$. There was no difference in DNA fragmentation between isolates belonging to genomospecies A and B $(1.66 \pm 0.10$
$\mathrm{A}_{370} \mathrm{~nm}$ versus $1.54 \pm 0.13 \mathrm{~A}_{370} \mathrm{~nm}$, respecively; $P=$ $0.45)$, nor between isolates in AFLP groups 1 and 2 $\left(1.72 \pm 0.10\right.$ versus $1.52 \pm 0.08 \mathrm{~A}_{370} \mathrm{~nm}$, respectively; $P$ $=0.15)$.

Epithelial cells inoculated with isolates from AFLP cluster 1 exhibited higher metabolic activity (i.e., MTT value) than those inoculated with AFLP cluster 2 isolates $(147.7 \pm 2.8$ versus $134.6 \pm 4.0 \%$, respectively; $P=$ 0.04). Likewise, metabolic activity in epithelial cells inoculated with isolates from healthy individuals was higher than that for isolates from diarrheic individuals $(147.4 \pm 2.9 \%$ versus $134.7 \pm 4.0 \%$, respectively; $P=$ 0.049). Mean metabolic activity did not differ between isolates from genomospecies A and B (144.9 $\pm 3.6 \%$ versus $132.3 \pm 7.0 \%$, respectively; $P=0.13)$. Metabolic activity was positively correlated with DNA fragmentation $\left(\mathrm{R}^{2}=0.47 ; P=0.007\right)$.

\section{Expression of IL-8}

All C. concisus isolates and C. jejuni 81-176 increased the expression of epithelial IL-8 mRNA more than twofold (Table 4). In contrast, IL-8 mRNA expression in monolayers treated with non-pathogenic E. coli HB101 $(0.94 \pm 0.17$ fold $)$ was similar to that of the sterile broth control (assigned a value of 1). IL-8 mRNA expression was higher in epithelial cells treated with isolates from AFLP cluster 1 compared to cells treated with AFLP cluster 2 isolates $(5.03 \pm 0.49$ fold versus $3.80 \pm 0.30$ fold, respectively; $P=0.04$ ). Mean IL-8 expression did not differ between $C$. concisus isolates belonging to genomospecies A and B (4.63 \pm 0.57 fold versus $4.27 \pm 0.35$ fold, respectively; $P=0.62$ ), nor between isolates from healthy and diarrheic humans $(4.44 \pm 0.72$ fold versus $4.12 \pm 0.29$ fold, respectively; $P=0.64$ ). Interleukin- 8 expression was not correlated with invasion $\left(\mathrm{R}^{2}=0.002\right.$; $P=0.87)$ or translocation $\left(\mathrm{R}^{2}=0.14 ; P=0.19\right)$.

\section{Toxin genes}

The CDT B gene was not detected in any of the C. concisus isolates, but was present in $C$. jejuni 81-176 (Additional file 3 ). The zot gene was detected in $80 \%$ of $C$. concisus isolates from healthy humans (i.e., four of five isolates), $22 \%$ of isolates from diarrheic humans (i.e., two of nine isolates), and the type strain. The S-layer $R T X$ gene was present in C. concisus CHRB3287 and CHRB2004, although amplification was weak for the latter isolate. The zot and S-layer RTX genes were not detected in C. jejuni 81-176.

\section{Discussion}

The observed high level of genetic diversity amongst the isolates of C. concisus is in agreement with previous studies $[1,2,10]$, and highlights the complex nature of this species. Cluster analysis of AFLP profiles indicated that 
Table 3 Hemolysis, DNA fragmentation, cytotoxicity, and metabolic activity of Campylobacter concisus isolates ${ }^{\text {a }}$

\begin{tabular}{|c|c|c|c|c|c|}
\hline Isolate & $\begin{array}{c}\text { AFLP } \\
\text { Cluster } \\
\end{array}$ & $\begin{array}{c}\text { Hemolysis }^{b} \\
(\%)\end{array}$ & $\begin{array}{c}\text { DNA fragmentation }{ }^{\mathrm{c}} \\
\left(\mathrm{A}_{370} \mathrm{~nm}\right)\end{array}$ & $\begin{array}{c}\text { Cytotoxicity } \\
(\%)\end{array}$ & $\begin{array}{c}\text { Metabolic activity } \\
(\% \text { control })\end{array}$ \\
\hline CHRB2004 & 1 & $60.2 \pm 14.4$ & $1.84 \pm 0.17^{d}$ & $1.23 \pm 0.21$ & $139.4 \pm 7.4$ \\
\hline CHRB3287 & 1 & $45.6 \pm 16.9$ & $1.83 \pm 0.13^{d}$ & $1.48 \pm 0.16$ & $146.8 \pm 9.2$ \\
\hline CHRB2011 & 1 & $60.5 \pm 9.8$ & $1.63 \pm .0 .05^{d}$ & $0.88 \pm 0.22$ & $151.9 \pm 7.5$ \\
\hline CHRB3290 & 1 & $81.1 \pm 4.5$ & $1.91 \pm 0.14^{d}$ & $0.94 \pm 0.19$ & $155.7 \pm 2.3$ \\
\hline CHRB1609 & 1 & $72.3 \pm 9.4$ & $1.37 \pm 0.18$ & $1.11 \pm 0.34$ & $144.5 \pm 4.4$ \\
\hline CHRB1794 & 2 & $70.9 \pm 10.1$ & $1.32 \pm 0.19$ & $1.42 \pm 0.15$ & $137.9 \pm 2.9$ \\
\hline CHRB6 & 2 & $41.2 \pm 11.6$ & $1.12 \pm 0.26$ & $1.43 \pm 0.18$ & $105.1 \pm 26.2^{\mathrm{e}}$ \\
\hline CHRB1569 & 2 & $47.0 \pm 12.0$ & $1.38 \pm 0.17$ & $1.29 \pm 0.26$ & $139.2 \pm 7.0$ \\
\hline CHRB2691 & 2 & $62.1 \pm 14.3$ & $1.62 \pm 0.07^{d}$ & $1.89 \pm 0.15$ & $133.5 \pm 10.3$ \\
\hline CHRB2370 & 2 & $44.9 \pm 12.0$ & $1.69 \pm 0.14^{d}$ & $1.46 \pm 0.08$ & $142.8 \pm 6.5$ \\
\hline CHRB2050 & 2 & $64.3 \pm 15.4$ & $1.41 \pm 0.07$ & $0.97 \pm 0.15$ & $131.0 \pm 7.1$ \\
\hline CHRB563 & 2 & $34.6 \pm 13.9$ & $1.55 \pm 0.23^{d}$ & $1.25 \pm 0.20$ & $138.0 \pm 10.2$ \\
\hline CHRB3152 & 2 & $30.7 \pm 15.4$ & $1.89 \pm 0.16^{d}$ & $1.28 \pm 0.15$ & $141.0 \pm 6.0$ \\
\hline CHRB3235 & 2 & $32.1 \pm 18.6$ & $1.69 \pm 0.12^{d}$ & $1.14 \pm 0.16$ & $143.2 \pm 6.3$ \\
\hline LMG7788 & 1 & $61.5 \pm 10.8$ & $1.54 \pm 0.08^{d}$ & $0.71 \pm 0.10$ & $140.8 \pm 5.2$ \\
\hline C. jejuni 81-176 & - & $75.6 \pm 3.7$ & $1.68 \pm 0.25^{d}$ & $4.53 \pm 0.31^{d}$ & $143.7 \pm 5.7$ \\
\hline Broth control & - & $0.44 \pm 0.14$ & $0.69 \pm 0.12$ & $0.96 \pm 0.34$ & 100 \\
\hline $\mathrm{H}_{2} \mathrm{O}_{2}$ & - & - & $1.38 \pm 0.22$ & $6.15 \pm 1.66^{\mathrm{d}}$ & $259.5 \pm 13.5$ \\
\hline Camptothecin & - & - & $2.23 \pm 0.40^{d}$ & $1.39 \pm 0.28$ & $177.5 \pm 9.2$ \\
\hline
\end{tabular}

${ }^{\text {aD }}$ ata are means \pm SEM, $n=3$.

${ }^{b}$ Percent total hemolysis of sheep erythrocytes for $1 / 8$ dilution of Campylobacter inoculum.

${ }^{\mathrm{c}}$ Assays conducted using T84 monolayers.

${ }^{\mathrm{d}} \mathrm{P}<0.05$ relative to the broth control treatment.

esloughing of epithelial cells noted in two of three repetitions.

the isolates examined in the current study comprised at least two distinct clusters. Similarly, Aabenhus et al. [1] denoted four AFLP clusters among 62 C. concisus isolates of which the majority $(\mathrm{n}=56)$ were assigned to one of two main clusters. Results of PCR assays targeting the 23S rRNA and cpn60 genes largely corresponded with the AFLP grouping, and lend support to the suggested genetic relationship between the isolates.

As C. concisus is a common inhabitant of the oral cavity, it is to be expected that it may be isolated from both healthy and diarrheic individuals. Examining isolates from healthy individuals, it was observed that the majority of isolates belonged to genomospecies $\mathrm{A}$ and their AFLP profiles clustered together (AFLP cluster 1) along with the type stain of oral origin. This AFLP cluster also included one genomospecies A isolate (CHRB 1609) from a diarrheic individual. Further studies are needed to determine whether this group of isolates represents inhabitants of the oral cavity that have survived gastrointestinal transit or whether they are intestinalassociated.

The majority (94\%) of isolates from diarrheic individuals were assigned to ALFP cluster 2. Among these isolates, $71 \%$ were assigned to genomospecies B, while only $11 \%$ of diarrheic isolates belonged to genomospecies A. Engberg et al. [2] reported a similar predominance of genomospecies $\mathrm{B}$ isolates among diarrheic fecal isolates, of which $33 \%$ and $67 \%$ were assigned to genomospecies A and B, respectively. Likewise, Aabenhus et al. [1] reported that $34 \%$ and $53 \%$ of fecal isolates from diarrheic patients were assigned to genomospecies $\mathrm{A}$ and $\mathrm{B}$, respectively. Our observation that isolates from genomospecies B were exclusively obtained from diarrheic individuals suggests a potential role for these isolates in intestinal disease. A comparative molecular examination of strains belonging to genomospecies $\mathrm{A}$ and $B$ may shed light on their respective pathogenic potential.

Examination of the pathogenic properties amongst $C$. concisus isolates determined that epithelial invasion and translocation were higher for isolates assigned to AFLP cluster 2 (of which 94\% were from diarrheic individuals). Additionally, epithelial translocation was higher for isolates belonging to genomospecies B (of which all isolates were from diarrheic individuals). This is of potential clinical relevance as invasiveness and translocation 


\begin{tabular}{|c|c|c|}
\hline Isolate & $\begin{array}{l}\text { AFLP } \\
\text { cluster }\end{array}$ & $\begin{array}{l}\text { IL-8 mRNA expression } \\
\text { (fold induction }{ }^{\text {b }} \text { ) }\end{array}$ \\
\hline CHRB2004 & 1 & $4.65 \pm 1.82$ \\
\hline CHRB3287 & 1 & $6.13 \pm 1.14$ \\
\hline CHRB2011 & 1 & $5.76 \pm 1.16$ \\
\hline CHRB3290 & 1 & $3.35 \pm 0.63$ \\
\hline CHRB1609 & 1 & $5.28 \pm 1.77$ \\
\hline CHRB1794 & 2 & $3.92 \pm 0.91$ \\
\hline CHRB6 & 2 & $4.53 \pm 0.89$ \\
\hline CHRB1569 & 2 & $4.11 \pm 0.93$ \\
\hline CHRB2691 & 2 & $3.49 \pm 1.51$ \\
\hline CHRB2370 & 2 & $5.46 \pm 1.67$ \\
\hline CHRB2050 & 2 & $2.61 \pm 1.01$ \\
\hline CHRB563 & 2 & $3.92 \pm 2.51$ \\
\hline CHRB3152 & 2 & $3.75 \pm 0.42$ \\
\hline CHRB3235 & 2 & $2.30 \pm 0.25$ \\
\hline LMG7788 & 1 & $4.53 \pm 0.81$ \\
\hline C. jejuni 81-176 & - & $6.55 \pm 1.35$ \\
\hline E. coli HB101 & - & $0.94 \pm 0.17$ \\
\hline
\end{tabular}

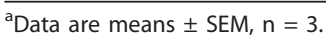

${ }^{b}$ Expression of IL-8 relative to basal level of expression (assigned a value of 1 ). Data were normalized using the housekeeping gene C1orf33f.

ability are the only factors definitively correlated with enteritis in C. jejuni-infected patients [26] and are likely associated with inflammatory responses and occasional bacteraemia observed with $C$. concisus infections [27]. To our knowledge, this is the first study to report differences in pathogenicity between the two main $C$. concisus genomospecies, further supporting the likelihood that isolates belonging to AFLP cluster 2/genomospecies B incite enteritis in humans.

All of the clinical $C$. concisus isolates examined in the current study caused hemolysis of sheep erythrocytes, consistent with previous observations of hemolytic phospholipase activity in all C. concisus genomospecies A and B isolates from diarrheic children [20]. As such, hemolytic activity appears to be a general characteristic of this species. Hemolysins are involved in pathogenesis and host colonization in other taxa [28], thus it was an unexpected observation that $C$. concisus genomospecies A isolates exhibited greater mean hemolysis than isolates belonging to genomospecies $\mathrm{B}$. We also observed that hemolytic activity by $C$. concisus was inversely correlated with epithelial adherence and invasion. Staphylococcus aureus exhibits a similar inverse correlation that is attributed to interference of its $\alpha$-hemolysin with epithelial $\beta 1$-integrins that mediate host-cell interactions [29]. Moreover, lower amounts of $\alpha$-hemolysin are produced by invasive $S$. aureus isolates from endocarditis patients compared to less-invasive isolates from open wounds [30]. Whether C. concisus hemolysin also interferes with epithelial receptors that promote adherence and invasion is unknown, and additional studies are warranted.

Another unexpected finding was that isolates from healthy individuals induced greater mean epithelial DNA fragmentation and metabolic activity compared to those from diarrheic individuals, and these variables were positively correlated. DNA fragmentation is used as an indicator of cell death. The two primary modes of cell death, namely apoptosis and necrosis, can be distinguished on the basis of physiologic features. DNA fragmentation can be present in both processes; however, during apoptosis, cell membranes typically remain intact, whereas during necrosis, cellular integrity is rapidly disrupted leading to the release of cytoplasmic contents (including lactate dehydrogenase) into the surrounding environment ("cytotoxicity"). Based on this definition, four isolates from healthy individuals (CHRB2004, CHRB3235, CHRB3287, and CHRB3290) and two isolates from diarrheic humans (CHRB2370 and CHRB3152) induced cell death consistent with apoptosis. While apoptosis can be mediated via CDT [18], it is unlikely that CDT was involved in the apoptosis given that we did not detect the CDTB gene in any of the strains included in our study. Furthermore, we did not find any genes with similar sequence to the CDTB gene using a BLAST search of the published C. concisus genome (NCBI accession number NC_009802), indicating that other factors (i.e. opposed to the CDT) may be responsible. The role that Campylobacter-induced epithelial cell death plays in pathogenesis is currently poorly understood; hence, the clinical significance of these findings for $C$. concisus remains to be determined.

Metabolic activity can be measured using the MTT assay in which metabolically active epithelial cells reduce a yellow tetrazolium salt (MTT) to purple formazan crystals that can be spectrophotometrically quantified. All of the isolates that we examined, except one isolate that caused epithelial sloughing (CHRB6), induced higher MTT values (> 130\%) than the control, indicating that epithelial metabolic activity is increased by $C$. concisus. Some clinical strains of $C$. jejuni have also been reported to cause similar increases in epithelial MTT values [31]. Given the short incubation period for the MTT assay, we conclude that the increased values most likely reflect an increase in metabolic activity due to cellular stress rather than an increase in epithelial cell numbers due to proliferation. The observed correlation between metabolic activity and DNA fragmentation may be a consequence of the increased energy demands required to sustain the apoptotic process (i.e., apoptotic DNA fragmentation is an ATP-dependent process [32]). 
The chemokine, IL- 8 is a major mediator of inflammation. In the current study, all $C$. concisus isolates induced transcription of IL-8 in epithelial monolayers (> 2-fold) as has been previously reported for C. jejuni [19] and C. concisus [33]. Campylobacter jejuni induces epithelial IL-8 secretion by at least two independent mechanisms, one of which requires invasion and the other that is CDT-dependent $[19,34]$. We observed that induction of IL-8 transcription by $C$. concisus was not correlated with invasion. Man et al. also recently showed that three $C$. concisus strains stimulated production of IL-8 in intestinal epithelial irrespective of their invasive ability [33]. Thus in contrast to $C$. jejuni, it appears that factors other than invasion or CDT (which appears to be lacking in this species) are responsible for the up-regulation of IL- 8 incited by $C$. concisus. The observation that expression of IL- 8 mRNA was greater in epithelial cells treated with isolates from AFLP cluster 1 compared to isolates from cluster 2 was unexpected and suggests that these isolates may have pathogenic potential.

We identified genes encoding S-layer RTX and the zonnula occludins toxin in some of the isolates, confirming initial reports of these toxin genes in C. concisus [21]. Surprisingly, the zot gene was more prevalent in isolates from healthy (80\%) compared to diarrheic (22\%) humans. The clinical significance of this observation remains to be determined. Although Zot has been shown to disrupt epithelial tight junctions, we did not observe any changes in permeability or TER of epithelial monolayers throughout the $3 \mathrm{~h}$ incubation period for any of the isolates. This is contrary to the observation of Man et al., that $C$. concisus caused increased epithelial permeability, decreased TER, and loss of membraneassociated zonnula occludens and occludin in epithelial monolayers [33]. Possible reasons for this discrepancy include variation in methodology between the two studies (i.e., Man et al. inoculated Caco-2 cells with an MOI of 200, and assessed barrier function 6 h-post inoculation.).

\section{Conclusion}

In summary, two main genomospecies were identified among fecal isolates of $C$. concisus from healthy and diarrheic individuals. The genomospecies differed with respect to clinical presentation and pathogenic properties, which is consistent with the hypothesis that certain genomospecies have different pathogenic potential. AFLP cluster 2 was predominated by isolates belonging to genomospecies $\mathrm{B}$ and those from diarrheic individuals. Isolates from this cluster displayed higher mean epithelial invasion and translocation than cluster 1 isolates, consistent with a potential role in inflammatory diarrhea and occasional bacteraemia. In contrast, isolates assigned to AFLP cluster 1 belonged to genomospecies
A and were predominantly (but not strictly) isolated from healthy individuals. Isolates assigned to this cluster induced greater expression of epithelial IL-8 mRNA and more frequently contained genes coding for the zonnula occludins toxin and the S-layer RTX. Furthermore, isolates from healthy individuals induced greater apoptotic DNA fragmentation and increased metabolic activity than did isolates from diarrheic individuals, and isolates assigned to genomospecies A (of which the majority were from healthy individuals) exhibited higher haemolytic activity compared to genomospecies B isolates. This suggests that isolates from this cluster may also cause disease, albeit via different mechanisms than isolates from AFLP cluster 2. AFLP cluster 1 contains a reference strain isolated from the oral cavity, thus it is possible that this cluster contains isolates that are primarily periodontal pathogens.

While in vitro pathogenicity assessments are informative, they do not necessarily correspond with the ability of an isolate to cause disease in vivo. Clearly, further studies, particularly in vivo, are needed to confirm that these genetically distinct groups of $C$. concisus indeed differ in their ability to cause intestinal disease. In this regard, comparative genomic and pathogenicity examinations using animal models have been initiated.

\section{Methods}

\section{Bacterial isolates and growth conditions}

A total of 23 C. concisus isolates recovered from different individuals were used in this study (Table 1). These included five isolates recovered from the stools of healthy volunteers (i.e., individuals that exhibited no recent symptoms of enteritis), 17 isolates obtained from stools of diarrheic humans, and the type strain of $C$. concisus isolated from the oral cavity of a healthy human (LMG7788; = CCUG 13144; = ATCC 33237). Isolates were collected from people residing in the Chinook Health Region of Southwestern Alberta, Canada. These isolates were originally collected as part of a larger study [35]. Scientific and ethics approval for stool collection was obtained from the Regional Ethics Committee of the former CHR and from the University of Lethbridge Human Subject Research Committee. Campylobacter jejuni 81-167 [36] was used as a positive pathogen control for all pathogenicity assays. In addition, the non-pathogenic Escherichia coli HB101 was used as a negative pathogen control for measuring epithelial IL- 8 expression in response to the presence of bacteria. Isolates were stored at $-80^{\circ} \mathrm{C}$ in Columbia broth (Difco, Detroit, MI) containing 40\% glycerol. With the excepiton of $E$. coli which was grown in an aerobic enviornment, inocula of $C$. concisus for cell culture assays were prepared by growing isolates for 14-16 $\mathrm{h}$ in Columbia broth $\left(37^{\circ} \mathrm{C}, 100 \mathrm{rpm}\right)$ in a microaerobic 
atmosphere (consisting of $5 \% \mathrm{O}_{2}, 10 \% \mathrm{CO}_{2}, 30 \% \mathrm{H}_{2}$ and balance nitrogen).

\section{S rRNA gene sequence}

Genomic DNA was extracted using a DNAeasy Tissue kit (Qiagen Inc., Mississauga, ON) according to the manufacture's instructions. The 16S rRNA gene was PCR amplified using the primers UNI27F and UNI1492R [37] (Table 5) and the resultant product was used as template for sequencing. A BigDye Terminator kit (Applied Biosystems, Foster City, CA) along with universal primers (Table 5) were used for sequencing the near full-length 16s rRNA gene according to the manufacturer's instructions. Sequence reactions were separated with an ABI 3130 automated DNA sequencer (Applied Biosystems). Sequences were analyzed using Sequencher software (Gene Codes, Ann Arbor, MI) and compared directly with the NCBI non-redundant nucleotide database using BLASTN.

\section{Amplified fragment length polymorphism analysis} Campylobacter concisus isolates were genotyped using the AFLP protocol described by Kokotovic and On [38]. Briefly, genomic DNA (125 ng) was digested with Cps6I $(10 \mathrm{U})$ in $\mathrm{Y}+/$ Tango Buffer (MBI) for $1 \mathrm{~h}$ at $37^{\circ} \mathrm{C}$. BglII $(10 \mathrm{U})$ was then added, and digestion was continued for one additional hour. Restriction site-specific adaptors (Table 5) were then ligated to the digested fragments for $2 \mathrm{~h}$ at room temperature. PCR amplification of the ligation mixture (diluted 10-fold) was carried out using primers BGL2F-0 and CSP6I-A (Table 5) for 35 cycles with an annealing temperature of $54^{\circ} \mathrm{C}$. The final products were separated with an ABI 3130 automated DNA sequencer (Applied Biosystems). To analyze AFLP profiles, fragments ranging from 75 to $500 \mathrm{bp}$ and the 500LIZ Genescan molecular mass standard were imported and compared using the BioNumerics 4.01 software (Applied Maths, Kortrijk, Belgium). Relationship of AFLP profiles ("curves") were inferred by use of the Pearson-product-moment correlation coefficient (applying 2\% optimization) and clustered by the unweighted pair group with mathematical average (UPGMA) method. To ensure reproducibility, AFLP analysis was conducted twice for isolate, and one representative of each AFLP profile was used for cluster analysis.

\section{PCR for 23S rRNA, cpn60, CDT B, S-layer RTX, and zot genes}

Primers for PCR are listed in Table 5. PCR amplification of the 23S rRNA gene was conducted according to the method of Bastyns et al. [11], except that the two reverse primers (CON1 and CON2) were used independently rather than as a mixture. Isolates amplifying with either MUC1/CON1 or MUC1/CON2 primers were assigned to genomospecies A or B, respectively. Campylobacter concisus-specific nested-PCR amplification of the chaperonin gene (cpn60) was conducted using the primers Ccon-cpn_66f and Ccon_cpn_423r for 25 cycles with an annealing temperature of $53^{\circ} \mathrm{C}$ [35]. The resultant PCR product was used as a template for a second round of PCR with the nested primers Ccon_cpn_72f and Ccon_cpn_342r for 30 cycles with an annealing temperature of $53^{\circ} \mathrm{C}$. PCR for the $C D T B$ gene was conducted using the primers P5 and P6 (Table 5) for 30 cycles with an annealing temperature of $65^{\circ} \mathrm{C}$. PCR for the $S$-layer RTX gene was conducted using the primers FCCC13826_1838 and RFCCC13826_1838 (Table 5) for 30 cycles with an annealing temperature of $58^{\circ} \mathrm{C}$. PCR for the $z o t$ gene was conducted using the primers FCCC13826_2075 and RFCCC13826_2075 for 30 cycles with an annealing temperature of $56^{\circ} \mathrm{C}$.

\section{Intestinal epithelial cell culture and inoculation}

T84 human colonic epithelial cells (passages 7 to 20; ATCC, Manassas, VA) were grown in DMEM/Ham F12 plus $10 \%$ fetal bovine serum, $200 \mathrm{mM} \mathrm{L}$-glutamine, $100 \mathrm{U} / \mathrm{ml}$ penicillin, $100 \mu \mathrm{g} / \mathrm{ml}$ streptomycin, $80 \mu \mathrm{g} / \mathrm{ml}$ tylosin (all from Sigma, Oakville, ON), and incubated at $37^{\circ} \mathrm{C}$ and $5 \% \mathrm{CO}_{2}$. For cell culture assays, confluent T84 monolayers were washed twice and media was replaced with antibiotic-free DMEM/Ham F12. Monolayers were inoculated with sterile Columbia broth (= control) or Campylobacter to achieve a multiplicity of infection of $100 \mathrm{CFU}$ per epithelial cell, and incubated for $3 \mathrm{~h}$ at $37^{\circ}$ C. Due to the intensive nature of the assays for assessment of pathogenic potential (i.e., adherence, invasion, translocation, hemolytic ability, and cytotoxicity), representative isolates of $C$. concisus from diarrheic and healthy humans were examined for pathogenicity ( $\mathrm{n}=5$ from AFLP cluster 1, $\mathrm{n}=9$ from AFLP cluster 2).

\section{Adherence and invasion}

T84 enterocyte monolayers were grown in 24-well plates and inoculated as described above. Following incubation, monolayers were washed three times with PBS. To assess adherence, monolayers were lysed with $0.1 \%$ Triton X-100 in PBS for $10 \mathrm{~min}$ at room temperature on an orbital shaker. Following lysis, bacteria were enumerated by plating ten-fold serial dilutions onto Karmali agar (Oxoid, Nepean, ON). Invasion was determined using a gentamicin protection assay. After incubation, monolayers were washed three times with PBS. Monolayers were then incubated for $2 \mathrm{~h}$ with fresh tissue culture medium containing gentamicin $(500 \mu \mathrm{g} / \mathrm{ml})$ to kill extracellular bacteria as previously described [39]. Following incubation, monolayers were washed, lysed and bacteria were enumerated as for the adherence assay. 
Table 5 Primers and adaptors used in this study

\begin{tabular}{|c|c|c|c|c|}
\hline Target $^{a}$ & Primer/Adaptor & Sequence $\left(5^{\prime}\right.$ to $\left.3^{\prime}\right)$ & Size (bp) & Reference \\
\hline- & Bgl II adaptor1 & CGGACTAGAGTACACTGTC & - & {$[38]$} \\
\hline- & Bgl II adaptor2 & GATCGACAGTGTACTCTAGTC & - & [38] \\
\hline- & Csp6 I adaptor1 & AATTCCAAGAGCTCTCCAGTAC & - & [38] \\
\hline- & Csp6 I adaptor2 & TAGTACTGGAGAGCTCTTGG & - & [38] \\
\hline- & BLG2F-0 & 6-fam-GAGTACACTGTCGATCT & - & {$[38]$} \\
\hline- & CSP61-A & GAGCTCTCCAGTACTACA & - & [38] \\
\hline \multirow[t]{4}{*}{ Universal 165 rRNA gene } & UNI27F & AGAGTTTGATCCTGGCTCAG & - & [37] \\
\hline & UNI338F & ACTCCTACGGGAGGCAG & - & {$[37]$} \\
\hline & UNI1100R & AGGGTTGCGCTCGTTG & - & {$[37]$} \\
\hline & UNI1492R & TACGG(C/T)TACCTTGTTACGACT & - & {$[37]$} \\
\hline \multirow[t]{3}{*}{ C. concisus $23 \mathrm{~S}$ rRNA gene } & MUC1 (forward) & ATGAGTAGCGATAATTGGG & - & [11] \\
\hline & CON1 (reverse) & CAGTATCGGCAATTCGCT & 306 & [11] \\
\hline & CON2 (reverse) & GACAGTATCAAGGATTTACG & 308 & [11] \\
\hline \multirow{2}{*}{$\begin{array}{l}\text { C. concisus cpn gene } \\
\text { (primary primers) }\end{array}$} & Ccon-cpn_66f & TATCGAAGTGAAACGTGGCA & 357 & [35] \\
\hline & Ccon_cpn_423r & GCTCAAGCACTGGCAATAAG & - & [35] \\
\hline \multirow{2}{*}{$\begin{array}{l}\text { C. concisus cpn gene } \\
\text { (nested primers) }\end{array}$} & Ccon_cpn_72f & AGTGAAACGTGGCATGGATA & 270 & [35] \\
\hline & Ccon_cpn_342r & GCATCTITTCAGGGTTTGTG & - & [35] \\
\hline \multirow{2}{*}{$\begin{array}{c}\text { C. concisus S-layer RTX gene } \\
\text { (YP_001465940.1) }\end{array}$} & FCCC13826_1838 & ACAGGCCATAAGTGGATTGC & 374 & This study \\
\hline & RCCC13826_1838 & CCGTCATAGTGGGCTCTCAT & - & This study \\
\hline \multirow{2}{*}{$\begin{array}{l}\text { C. concisus zot gene } \\
\text { (YP_001467422) }\end{array}$} & FCCC13826_2075 & TGCAAACCCTITGTGATGAA & 355 & This study \\
\hline & RCCC13826_2075 & CATGAGCCAGCTCAATCAAC & - & This study \\
\hline \multirow{2}{*}{$\begin{array}{l}\text { Human interleukin } 8 \text { gene } \\
\text { (NM_000584) }\end{array}$} & hIL-8f & TाTाGCCAAGGAGTGCTAAAGA & 194 & $P B{ }^{b}$ \\
\hline & hIL-8r & AACCCTCTGCACCCAGTTITC & - & $P B{ }^{b}$ \\
\hline \multirow{2}{*}{$\begin{array}{l}\text { Human Clorf33 gene } \\
\text { (NM_016183) }\end{array}$} & hC1orf33f & TCCAAGCGCGACAAGAAAGT & 102 & $P B{ }^{b}$ \\
\hline & hC1orf33r & GTAGGTGTCCACACATTTCCG & - & $P B{ }^{b}$ \\
\hline \multirow{2}{*}{$\begin{array}{c}\text { C. jejuni CDT B gene } \\
(\text { U51121) }\end{array}$} & P5 & GAATCCGTTGGCACTTGGAATTTGCAAGGC & 495 & {$[40]$} \\
\hline & P6 & GGATTCGTTAAAATCCCCTGCTATCATCCA & - & {$[40]$} \\
\hline
\end{tabular}

${ }^{\mathrm{a}}$ GenBank or NCBI protein accession number indicated in brackets.

${ }^{b}$ Primers sequences were obtained from the PrimerBank database http://pga.mgh.harvard.edu/primerbank/index.html.

A preliminary experiment was conducted to ensure that a bactericidal concentration of gentamicin was used for the invasion assay.

\section{Translocation and epithelial permeability}

T84 cells were seeded onto Transwell filters at $4 \times 10^{5}$ cells/filter $\left(5 \mu \mathrm{m}\right.$ pore size, $1.13 \mathrm{~cm}^{2}$; Costar, Corning
Inc. Corning, NY) and cultured as described above. Transepithelial electrical resistance (TER) was monitored with an electrovoltohmeter (World Precision Instruments, Sarasota, FL), and monolayers were used at confluence (TER $>1000 \Omega \times \mathrm{cm}^{2}$ ). Monolayers were inoculated as described above. Following incubation, the basolateral medium was serially diluted, spread onto 
Karmali agar and incubated microaerobically at $37^{\circ} \mathrm{C}$. Permeability was assayed as described previously [25]. Briefly, monolayers were washed with Ringer's solution, and a $3 \mathrm{kDa}$ FITC-dextran probe $(500 \mu \mathrm{l}, 100 \mathrm{mM}$ in Ringer's solution; Molecular Probes, Eugene, OR) was added to the apical compartment and $1 \mathrm{ml}$ of Ringer's solution was also added to the basal compartment. Following incubation for $3 \mathrm{~h}$ at $37^{\circ} \mathrm{C}$, samples were collected from the basal compartment and absorbance at $485 \mathrm{~nm}$ was measured.

\section{Hemolysis}

Hemolysis of sheep erythrocytes was measured as previously described [20]. In brief, C. concisus cells cultured in Columbia broth as described above were centrifuged $(8000 \times \mathrm{g}, 3 \mathrm{~min})$ and cell pellets were washed with sterile PBS, suspended in PBS to $1 \times 10^{9} \mathrm{CFU} / \mathrm{ml}$, and then serially diluted 2 -fold in PBS. Equal volumes $(100 \mu \mathrm{l})$ of cell suspension and sheep erythrocytes $(2 \% \mathrm{vol} / \mathrm{vol}$ in PBS) were mixed in a U-bottom 96-well plate. The plate was then incubated at $37^{\circ} \mathrm{C}$ under microaerobic conditions for $18 \mathrm{~h}$. A comparative negative control (without bacteria) was also incubated under similar conditions. A positive control for total hemolysis (100\%) was performed by replacing the same volume of bacterial cell suspension with distilled water. After incubation, the tubes were centrifuged at $1000 \times \mathrm{g}$ for $5 \mathrm{~min}$, and the $\mathrm{OD}_{490}$ of the supernatants for the $1 / 3$ dilution were measured. Data were reported as the percent total hemolysis of sheep erythrocytes (compared to the positive control).

\section{DNA fragmentation, cytotoxicity, and metabolic activity}

T84 monolayers were grown in 24-well plates and inoculated as described above. Control monolayers were also treated with camptothecin $(4 \mu \mathrm{M})$, hydrogen peroxide $\left(\mathrm{H}_{2} \mathrm{O}_{2}, 0.5 \mathrm{mM}\right)$, or sterile broth. Following incubation, DNA fragmentation was measured using a Cellular DNA Fragmentation ELISA kit (Roche Applied Science, Laval, QC) according to the manufacturer's protocol. Lactate dehydrogenase released into the surrounding tissue culture was measured using a Cytotoxicity Detection kit (Roche) according to the manufacturer's protocol. Metabolic activity (i.e. MTT assay) was measured using a Cell Proliferation Kit I (Roche) according to the manufacturer's protocol, except that gentamicin $(500 \mu \mathrm{g} / \mathrm{ml})$ was incorporated into the MTT solution.

\section{Interleukin-8 real-time quantitative PCR}

T84 monolayers were grown in six-well plates and inoculated with C. concisus and C. jejuni as described above. In addition, monolayers were inoculated at an MOI of 100 with $E$. coli HB101. Following incubation, the culture medium was removed and replaced with RNAlater $(3 \mathrm{ml} /$ well; Qiagen), and cells were stored at $4{ }^{\circ} \mathrm{C}$ until processed for RNA extraction ( $<1$ week). Total RNA was isolated using the RNeasy mini kit (Qiagen), according to the manufacturer's protocol. RNA was reverse transcribed using a QuantiTect reverse transcription kit (Qiagen) according to the manufacturer's protocol. PCR was conducted using an Mx3005P Stratagene thermocycler (Stratagene, Cedar Creek, TX). All PCR reactions were carried out in $20 \mu \mathrm{l}$ volumes and contained 1X QuantiTect SYBR Green PCR Master Mix (Qiagen), forward and reversed primers $(0.5 \mu \mathrm{M}$ each; Table 5$)$ and $2 \mu \mathrm{L}$ of $\mathrm{RT}$ reaction. Amplification conditions were 1 cycle at $95^{\circ} \mathrm{C}$ for $15 \mathrm{~min}$ followed by 40 cycles of $94^{\circ} \mathrm{C}$ for $15 \mathrm{~s}, 60^{\circ} \mathrm{C}$ for $30 \mathrm{~s}$, and $72^{\circ} \mathrm{C}$ for $30 \mathrm{~s}$. Melting curve analysis was conducted over a range of 55 to $95^{\circ} \mathrm{C}$ to assess specificity of amplification. Interleukin-8 expression was normalized to the housekeeper gene, C1orf33, and fold changes in expression relative to the sterile-broth control was calculated using the $2^{-\triangle \Delta C T}$ method.

\section{Statistical analysis}

Experiments were conducted at least three times on separate occasions (i.e., replicates). Each assay was conducted at least in duplicate (i.e., observations), and the mean value was used for analysis. Data are expressed as mean \pm SEM. All statistical calculations were performed with GraphPad InStat v.3.06 software (GraphPad Software Inc., San Diego, CA). Data with three or more treatments were compared by one way analysis of variance, followed by the protected Tukey-Kramer multiple comparison test. Data with two treatments were compared using an unpaired Student's $t$-test. Regression analysis was performed using Pearson correlation analysis. Statistical significance was established at $P<0.05$.

\section{Additional material}

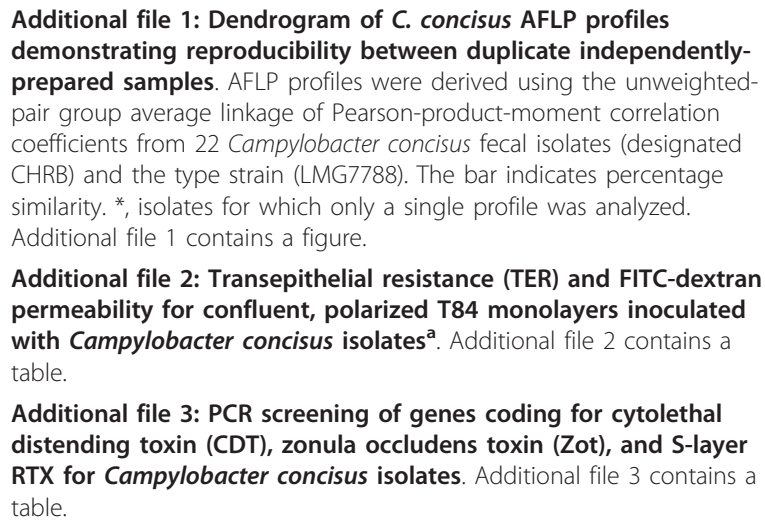

Additional file 2: Transepithelial resistance (TER) and FITC-dextran permeability for confluent, polarized T84 monolayers inoculated with Campylobacter concisus isolates ${ }^{\mathrm{a}}$. Additional file 2 contains a table.

Additional file 3: PCR screening of genes coding for cytolethal distending toxin (CDT), zonula occludens toxin (Zot), and S-layer RTX for Campylobacter concisus isolates. Additional file 3 contains a table.

\section{Acknowledgements}

We thank Jenny Gusse for conducting the AFLP genotyping and cluster analysis, sequencing the $16 \mathrm{~S}$ rRNA gene, and for designing and validating 
the C. concisus-specific cpn60 primers. We also thank Kathaleen House for isolating and conducting the initial characterization of C. concisus isolates. We wish to thank the anonymous reviewers of this manuscript for their insightful and constructive comments. This work was supported by a Peer Review Grant from Agriculture and Agri-Food Canada (Growing Forward initiative).

\section{Authors' contributions}

LDK participated in the design of the study, performed experiments, conducted data analysis, and drafted the manuscript. GDI participated in the design of the study and edited the manuscript. All authors approved the final manuscript.

Received: 2 February 2011 Accepted: 15 March 2011

Published: 15 March 2011

\section{References}

1. Aabenhus R, On SL, Siemer BL, Permin H, Andersen LP: Delineation of Campylobacter concisus genomospecies by amplified fragment length polymorphism analysis and correlation of results with clinical data. J Clin Microbiol 2005, 43(10):5091-5096.

2. Engberg J, Bang DD, Aabenhus R, Aarestrup FM, Fussing V, Gerner-Smidt P: Campylobacter concisus: an evaluation of certain phenotypic and genotypic characteristics. Clin Microbiol Infect 2005, 11(4):288-295.

3. Lindblom GB, Sjogren E, Hansson-Westerberg J, Kaijser B: Campylobacter upsaliensis, C. sputorum sputorum and C. concisus as common causes of diarrhoea in Swedish children. Scand J Infect Dis 1995, 27(2):187-188.

4. Vandamme P, Falsen E, Pot B, Hoste B, Kersters K, De Ley J: Identification of EF group 22 campylobacters from gastroenteritis cases as Campylobacter concisus. J Clin Microbiol 1989, 27(8):1775-1781.

5. Newell DG: Campylobacter concisus: an emerging pathogen? Eur J Gastroenterol Hepatol 2005, 17(10):1013-1014.

6. Schlenker C, Surawicz CM: Emerging infections of the gastrointestinal tract. Best Pract Res Clin Gastroenterol 2009, 23(1):89-99.

7. Tanner AC, Badger S, Lay CH, Listgarten MA, Visconti RA, Socransky SS: Wolinella gen. nov., Wolinella succinogenes (Vibrio succinogenes Wolin et al.) com. nov., and description of Bacteriodes gracilis sp. nov., Wolinella recta sp. nov., Campylobacter concisus sp. nov., and Eikenella corrodens from humans with periodontal disease. Int J Syst Bacteriol 1981, 31:432-445.

8. Macuch PJ, Tanner AC: Campylobacter species in health, gingivitis, and periodontitis. J Dent Res 2000, 79(2):785-792.

9. Engberg J, On SL, Harrington CS, Gerner-Smidt P: Prevalence of Campylobacter, Arcobacter, Helicobacter, and Sutterella spp. in human fecal samples as estimated by a reevaluation of isolation methods for Campylobacters. J Clin Microbiol 2000, 38(1):286-291.

10. Van Etterijck R, Breynaert J, Revets H, Devreker T, Vandenplas $Y$, Vandamme P, Lauwers S: Isolation of Campylobacter concisus from feces of children with and without diarrhea. J Clin Microbiol 1996, 34(9):2304-2306

11. Bastyns K, Chapelle S, Vandamme P, Goossens H, De Wachter R: Specific detection of Campylobacter concisus by PCR amplification of $23 \mathrm{~S}$ rDNA areas. Mol Cell Probes 1995, 9(4):247-250.

12. Daneshvar MI, Hollis DG, Steigerwalt AG, Whitney AM, Spangler L, Douglas MP, Jordan JG, MacGregor JP, Hill BC, Tenover FC, et al: Assignment of CDC weak oxidizer group 2 (WO-2) to the genus Pandoraea and characterization of three new Pandoraea genomospecies. J Clin Microbiol 2001, 39(5):1819-1826.

13. Mills JM, Lofthouse E, Roberts $P$, Karas JA: A patient with bacteraemia and possible endocarditis caused by a recently-discovered genomospecies of Capnocytophaga: Capnocytophaga genomospecies AHN8471: a case report. J Med Case Reports 2008, 2:369.

14. Szymanski CM, King M, Haardt M, Armstrong GD: Campylobacter jejuni motility and invasion of Caco-2 cells. Infect Immun 1995, 63(11):4295-4300.

15. Chen ML, Ge Z, Fox JG, Schauer DB: Disruption of tight junctions and induction of proinflammatory cytokine responses in colonic epithelial cells by Campylobacter jejuni. Infect Immun 2006, 74(12):6581-6589.

16. MacCallum A, Hardy SP, Everest PH: Campylobacter jejuni inhibits the absorptive transport functions of Caco-2 cells and disrupts cellular tight junctions. Microbiology 2005, 151(Pt 7):2451-2458.
17. Kalischuk LD, Inglis GD, Buret AG: Campylobacter jejuni induces transcellular translocation of commensal bacteria via lipid rafts. Gut Pathog 2009, 1(1):2.

18. Whitehouse CA, Balbo PB, Pesci EC, Cottle DL, Mirabito PM, Pickett CL: Campylobacter jejuni cytolethal distending toxin causes a G2-phase cell cycle block. Infect Immun 1998, 66(5):1934-1940.

19. Zheng J, Meng J, Zhao S, Singh R, Song W: Campylobacter-induced interleukin-8 secretion in polarized human intestinal epithelial cells requires Campylobacter-secreted cytolethal distending toxin- and Tolllike receptor-mediated activation of NF-kappaB. Infect Immun 2008, 76(10):4498-4508.

20. Istivan TS, Coloe PJ, Fry BN, Ward P, Smith SC: Characterization of a haemolytic phospholipase $\mathrm{A}(2)$ activity in clinical isolates of Campylobacter concisus. J Med Microbiol 2004, 53(Pt 6):483-493.

21. Kaakoush NO, Man SM, Lamb S, Raftery MJ, Wilkins MR, Kovach Z, Mitchell H: The secretome of Campylobacter concisus. Febs J 2010, 277(7):1606-1617.

22. Fasano A, Baudry B, Pumplin DW, Wasserman SS, Tall BD, Ketley JM, Kaper JB: Vibrio cholerae produces a second enterotoxin, which affects intestinal tight junctions. Proc Natl Acad Sci US A 1991, 88(12):5242-5246.

23. Braun $M$, Kuhnert $P$, Nicolet J, Burnens AP, Frey J: Cloning and characterization of two bistructural S-layer-RTX proteins from Campylobacter rectus. J Bacteriol 1999, 181(8):2501-2506.

24. Lally ET, Hill RB, Kieba IR, Korostoff J: The interaction between RTX toxins and target cells. Trends Microbiol 1999, 7(9):356-361.

25. Kalischuk LD, Inglis GD, Buret AG: Strain-dependent induction of epithelial cell oncosis by Campylobacter jejuni is correlated with invasion ability and is independent of cytolethal distending toxin. Microbiology 2007, 153(Pt 9):2952-2963.

26. Everest PH, Goossens H, Butzler JP, Lloyd D, Knutton S, Ketley JM, Williams PH: Differentiated Caco-2 cells as a model for enteric invasion by Campylobacter jejuni and C. coli. J Med Microbiol 1992, 37(5):319-325.

27. Lastovica AJ, Allos BM: Clinical significance of Campylobacter and related species other than Campylobacter jejuni and Campylobacter coli. In Campylobacter. 3 edition. Edited by: Nachamkin I, Szymanski CM, Blaser MJ. Washington, DC: American Society for Microbiology; 2008:123-149.

28. Gonzalez MR, Bischofberger M, Pernot L, van der Goot FG, Freche B: Bacterial pore-forming toxins: the (w)hole story? Cell Mol Life Sci 2008, 65(3):493-507.

29. Liang $X, J i$ Y: Alpha-toxin interferes with integrin-mediated adhesion and internalization of Staphylococcus aureus by epithelial cells. Cell Microbiol 2006, 8(10):1656-1668.

30. Nozohoor S, Heimdahl A, Colque-Navarro P, Julander I, Soderquist B, Mollby R: Virulence factors of Staphylococcus aureus in the pathogenesis of endocarditis. A comparative study of clinical isolates. Zentralb/ Bakteriol 1998, 287(4):433-447.

31. Coote JG, Stewart-Tull DE, Owen RJ, Bolton FJ, Siemer BL, Candlish D, Thompson DH, Wardlaw AC, On SL, Candlish A, et al: Comparison of virulence-associated in vitro properties of typed strains of Campylobacter jejuni from different sources. J Med Microbiol 2007, 56(Pt 6):722-732.

32. Nakamura N, Wada Y: Properties of DNA fragmentation activity generated by ATP depletion. Cell Death Differ 2000, 7(5):477-484.

33. Man SM, Kaakoush NO, Leach ST, Nahidi L, Lu HK, Norman J, Day AS, Zhang L, Mitchell HM: Host attachment, invasion, and stimulation of proinflammatory cytokines by Campylobacter concisus and other nonCampylobacter jejuni Campylobacter species. J Infect Dis 2010, 202(12):1855-1865.

34. Hickey TE, McVeigh AL, Scott DA, Michielutti RE, Bixby A, Carroll SA, Bourgeois AL, Guerry P: Campylobacter jejuni cytolethal distending toxin mediates release of interleukin-8 from intestinal epithelial cells. Infect Immun 2000, 68(12):6535-6541.

35. Inglis GD, Boras VF, Houde A: Enteric campylobacteria and RNA viruses associated with healthy and diarrheic humans in the Chinook Heath Region of Southwestern Alberta. J Clin Microbiol 2011, 49(1):209-219.

36. Korlath JA, Osterholm MT, Judy LA, Forfang JC, Robinson RA: A pointsource outbreak of campylobacteriosis associated with consumption of raw milk. J Infect Dis 1985, 152(3):592-596.

37. Lane DJ: 16S/23S rRNA sequencing. In Nucleic Acid Techniques in Bacterial Systematics. Edited by: Stackebrandt E, Goodfellow M. Chichester: John Wiley 1991:115-175. 
38. Kokotovic B, On SL: High-resolution genomic fingerprinting of Campylobacter jejuni and Campylobacter coli by analysis of amplified fragment length polymorphisms. FEMS Microbiol Lett 1999, 173(1):77-84.

39. Monteville MR, Yoon JE, Konkel ME: Maximal adherence and invasion of INT 407 cells by Campylobacter jejuni requires the CadF outermembrane protein and microfilament reorganization. Microbiology 2003 149(Pt 1):153-165.

40. Purdy D, Buswell CM, Hodgson AE, McAlpine K, Henderson I, Leach SA: Characterisation of cytolethal distending toxin (CDT) mutants of Campylobacter jejuni. J Med Microbiol 2000, 49(5):473-479.

doi:10.1186/1471-2180-11-53

Cite this article as: Kalischuk and Inglis: Comparative genotypic and pathogenic examination of Campylobacter concisus isolates from diarrheic and non-diarrheic humans. BMC Microbiology 2011 11:53.

Submit your next manuscript to BioMed Central and take full advantage of:

- Convenient online submission

- Thorough peer review

- No space constraints or color figure charges

- Immediate publication on acceptance

- Inclusion in PubMed, CAS, Scopus and Google Scholar

- Research which is freely available for redistribution

Submit your manuscript at www.biomedcentral.com/submit 